\title{
Determination of Radiative Heat Transfer Coefficient at High Temperatures Using a Combined Experimental-Computational Technique
}

\author{
Václav Kočí, Jan Kočí, Tomáš Korecký, Jiří Maděra, Robert Černý \\ Department of Materials Engineering and Chemistry, Faculty of Civil Engineering, Czech Technical University in Prague, \\ Thákurova 7/2077, 16629 Prague, Czech Republic, Email: vaclav.koci@fsv.cvut.cz
}

\begin{abstract}
The radiative heat transfer coefficient at high temperatures is determined using a combination of experimental measurement and computational modeling. In the experimental part, cement mortar specimen is heated in a laboratory furnace to $600^{\circ} \mathrm{C}$ and the temperature field inside is recorded using built-in K-type thermocouples connected to a data logger. The measured temperatures are then used as input parameters in the three dimensional computational modeling whose objective is to find the best correlation between the measured and calculated data via four free parameters, namely the thermal conductivity of the specimen, effective thermal conductivity of thermal insulation, and heat transfer coefficients at normal and high temperatures. The optimization procedure which is performed using the genetic algorithms provides the value of the high-temperature radiative heat transfer coefficient of $3.64 \mathrm{~W} /\left(\mathrm{m}^{2} \mathrm{~K}\right)$.
\end{abstract}

Keywords: Radiative heat transfer coefficient, high temperatures, thermocouples, genetic algorithms, cement mortar.

\section{INTRODUCTION}

$\mathrm{D}$ URING the past several decades, computational modeling penetrated into most scientific and engineering disciplines, including the fire safety engineering. Basically, it became an integral part of the fire resistance assessment process of building materials, constructions or their parts, serving as an effective tool for the prediction of their behavior when exposed to fire [1]-[3].

The simulations are mostly based on fire scenarios, which are defined in ISO/TS 16733:2006 [4] in the form of fire curves, describing the development of air temperature in dependence on fire duration. One can use either nominal fire curves, which have many limitations on the one hand, but on the other, they are widely used because of their simplicity and uniformity, or parametric fire curves described in EN 1991-1-2 [5], which are more complex, respecting, e.g., the influence of openings, fire load density, geometry of compartment, etc. However, in most calculations there is an assumption that temperature of the air is equal to the temperature of material surface. That means, only Dirichlet's boundary condition is adopted which does not reflect the physical nature of heat transfer in a sufficient way. In order to describe it more precisely, it is essential to take into account the heat transfer coefficients in the calculations. They can be possibly included in the parametric fire curves, but only as a uniform value for all the compartment boundaries. Summarizing all these facts together, the presented deficiencies can lead, apparently, to a distortion of obtained results.

High-temperature measurements are generally characterized by typical distinctions, such as the necessity of application of specific measuring devices, high-temperature resistant probes or sensors. Due to the enhanced requirements for the experimental setup and equipment, the number of reported experimental measurements of heat transfer coefficients at high temperatures is very small. Most of the measurements were performed only at normal temperatures or they were not related to building physics. Using climatic chamber, K-type thermocouples, Pt 500 sensors, and infrared thermal imaging camera, Koca et al. [6] and Cholewa et al. [7] investigated the heat transfer coefficients of radiant heating systems of buildings. They analyzed the temperature range from 30 to $42{ }^{\circ} \mathrm{C}$ or $55^{\circ} \mathrm{C}$, respectively, which was appropriate to their objectives. However, even if they tried to measure higher temperatures, they would be limited by the temperature range of Pt 500 probes and climatic chamber. Other investigators determined the heat transfer coefficients at high temperatures, but their research was usually aimed at different issues or materials related to power engineering [8]-[10], foundry industry [11] or heat exchangers design [12]. This lack of experimental data can be the reason why the heat transfer coefficients at high temperatures have not been employed frequently so far in fire safety engineering or have been substituted by prescribed standard values [13] for normal temperatures.

In this paper, we introduce a combined experimentalcomputational method for the determination of heat transfer coefficients at high temperatures. The method is based on the experimental measurement of temperature field across the analyzed specimen exposed to high temperature. The experimental results are then utilized in a computational optimization process using genetic algorithms which provides the demanded heat transfer coefficient.

\section{MATERIALS \& METHODS}

\subsection{Sample preparation}

The investigated specimen made of cement mortar had cubic shape with the dimensions of $71 \mathrm{~mm} \times 71 \mathrm{~mm} \times 71 \mathrm{~mm}$. The mixture was composed of Portland cement, sand, water and plasticizer. The exact composition including specification of particular substances is given in Table 1. Bulk density of the investigated cement mortar was $2130 \mathrm{~kg} / \mathrm{m}^{3}$ according to EN 1015-10 [14]. 
Table 1. Mixture composition.

\begin{tabular}{|l|c|}
\hline Substance & Composition [\% by mass] \\
\hline Cement CEM I 42.5 R & 27.17 \\
\hline Sand 0-4 mm & 62.87 \\
\hline Water & 9.51 \\
\hline Plasticizer Sika 1035 & 0.45 \\
\hline
\end{tabular}

During the setting process, a K-type thermocouple set was built into the specimen (Fig.1.). The scheme of the set is presented in Fig.2., the distances of the particular thermocouple sensors from the face side are given in Table 2.

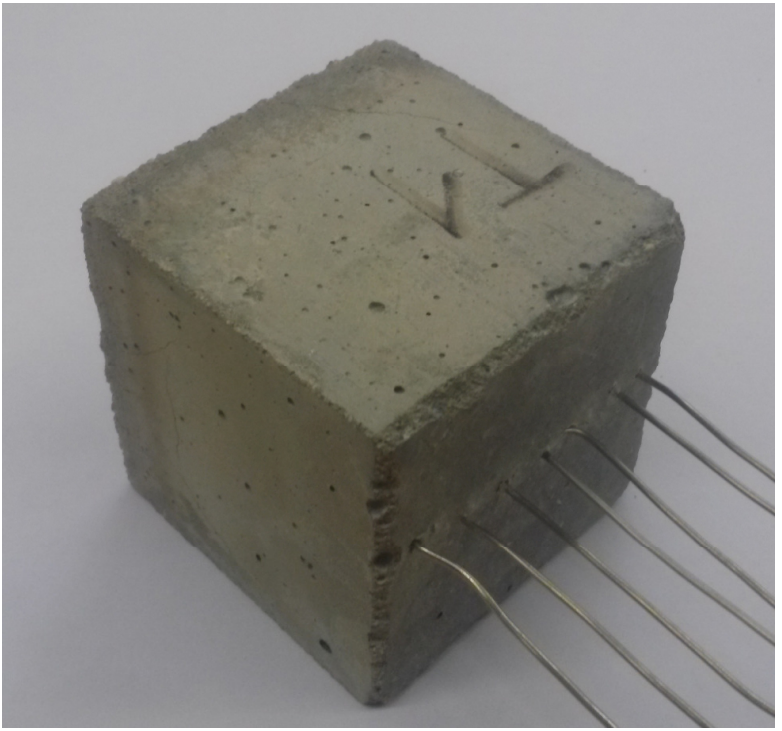

Fig.1. Investigated specimen with built-in K-type thermocouple set.

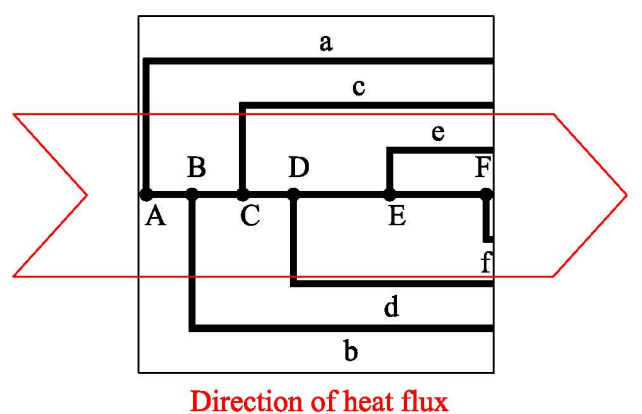

Fig.2. Scheme of the built-in thermocouple set.

Table 2. Distances of thermocouple sensors from the face side of the specimen.

\begin{tabular}{|c|c|c|}
\hline & Average distance $[\mathbf{m m}]$ & Standard deviation $[\mathbf{m m}]$ \\
\hline $\mathrm{a}$ & 70.55 & 0.39 \\
\hline $\mathrm{b}$ & 59.47 & 0.30 \\
\hline $\mathrm{c}$ & 49.61 & 0.45 \\
\hline $\mathrm{d}$ & 40.17 & 0.35 \\
\hline $\mathrm{e}$ & 20.43 & 0.39 \\
\hline $\mathrm{f}$ & 0.44 & 0.29 \\
\hline
\end{tabular}

\subsection{Experimental setup}

The laboratory furnace depicted in Fig.3. was used for exposing the specimen to a high-temperature environment. There was an opening in the door of the furnace, which was insulated by ceramic-fiber high-temperature resistant thermal insulation (produced by Morgan Thermal Ceramics) in a thickness of $40 \mathrm{~mm}$. The connection of the thermocouple set with the data logger was established through the insulation layer which was in contact with one face side of the specimen. Constant temperature inside the furnace was controlled by a built-in thermostat.

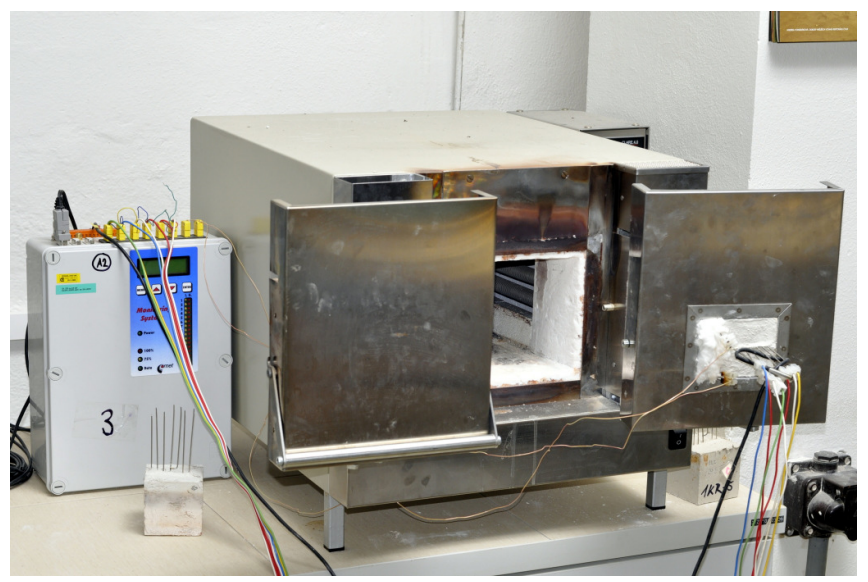

Fig.3. The laboratory furnace (illustrative image).

After the specimen was put into contact with the air in the furnace, the temperature field monitored by the thermocouple set was continuously recorded and after reaching the steady state, the experiment was terminated. Under ideal conditions, the temperature inside the specimen in all measured positions should be constant and equal to the temperature of the air in the furnace, after a certain period of time. However, due to the thermal losses through the insulation which is in contact with the front side of the specimen and due to the very high thermal conductivity of the thermocouple wires, the steady-state temperature field is not constant across the specimen but is slightly decreasing towards the furnace exterior. Then, the steady temperature difference between the front and back sides of the specimen creates the constant heat flux as depicted in Fig. 2.

\subsection{The method for determination of heat transfer coefficient}

Theoretically, assuming one-dimensional heat transport, the heat transfer coefficient $\alpha\left[\mathrm{W} /\left(\mathrm{m}^{2} \mathrm{~K}\right)\right]$ can be determined as

$$
\alpha=\frac{q}{T_{0}-T}
$$

where $q\left[\mathrm{~W} / \mathrm{m}^{2}\right]$ denotes the absolute value of the steadystate heat flux through the specimen, $T_{0}[\mathrm{~K}]$ is the temperature of the air inside the furnace and $T[\mathrm{~K}]$ is the temperature of the surface of the specimen adjacent to the air in the furnace. 
However, in the applied experimental setup one knows only the temperature of the air inside the furnace, which is preset and controlled by the furnace's thermostat. The surface temperature and the heat flux on the specimen surface, which is in contact with the air in the furnace, can be directly measured with great difficulties only, if ever. Moreover, the heat transport cannot be assumed as exactly one-dimensional because a perfect thermal insulation on the lateral sides of the specimen can hardly be achieved in any real experiment. The extrapolation of the measured temperatures inside the specimen, which has to be done to obtain the surface temperature, can bring further inaccuracies into the calculation.

Therefore, at the determination of the heat transfer coefficient in this paper, all the described imperfections of the experimental setup were taken into account and a complex computational representation of the experiment was created. The input parameters of the computational model included, besides the furnace air temperature, also the air temperature in the laboratory and the thermal properties of both the thermal insulation layer and the thermocouple wires. The model was applied in a series of computations aimed at the achievement of the best agreement of the calculated temperature field with the temperatures measured in the specimen by the thermocouple set. An optimization procedure using genetic algorithms was used for that purpose. The heat transfer coefficient was then obtained using the optimized temperature field.

\subsection{Methods of computational modeling}

Regarding the experimental setup, computational modeling was performed as three-dimensional. Because of the pre-drying of the specimen and high-temperature environment during the experiment which did not allow the presence of water in any phase, only heat transfer (in the steady-state mode) was assumed. The problem was solved by the finite element method, using the non-linear steadystate model in the computer code SIFEL [15].

The computational model of the experiment, depicted in Fig.4., was created using the GiD preprocessor [16]. Here, the gray color marks the analyzed specimen, pink color denotes the thermal insulation layer in the opening, and blue color marks the thermocouple wires installed in the specimen and coming through the insulation. The model assumes several simplifications for reducing the number of elements and thus the computing time. Because the temperature of the air inside the furnace was guarded by the thermostat, we excluded it from the model free parameters and used $T_{0}=600{ }^{\circ} \mathrm{C}$ in the Newton's boundary condition. Furthermore, only the heat losses through the insulation layer and thermocouple wires were taken into account; the heat leakage through the lateral sides of the furnace was neglected so that it was not necessary to include the whole furnace into the model. The boundary conditions expressing the temperature in the laboratory $\left(T_{0}=25^{\circ} \mathrm{C}\right)$ were thus applied only on the front side of the insulation, including the surface of the wires. After these simplifications, the constructed mesh comprised of 120621 nodes and 112888 elements.

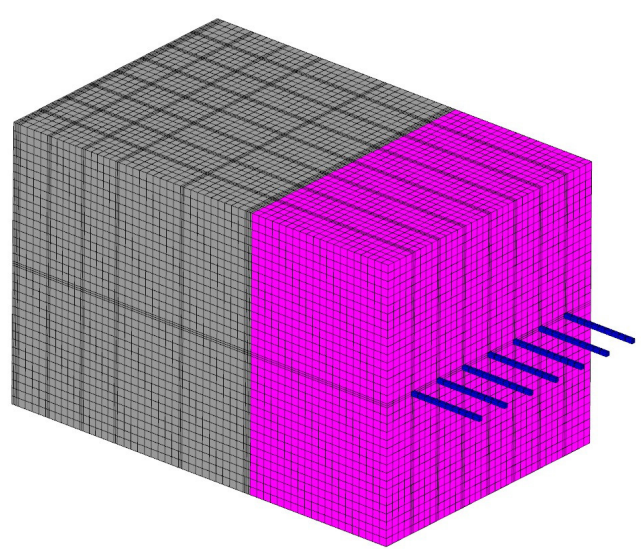

Fig.4. Computational model of the experiment.

Besides the geometry and space discretization of the experiment, several other input parameters entered the calculation of the steady-state temperature field. Some of them, such as temperature in the furnace and in the laboratory, were measured or preset. Thermal conductivity of the chromel-alumel thermocouple (K-type) was taken from Sundqvist [17] and extrapolated using logarithmic regression function with the coefficient of determination $R^{2}=0.9974$ (see Fig.5.).

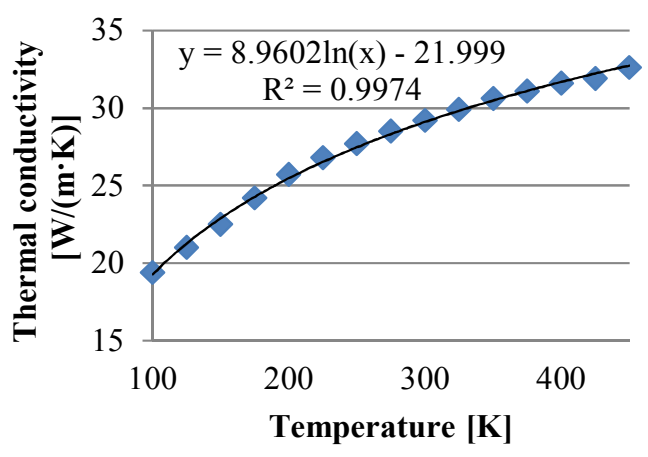

Fig.5. Thermal conductivity of thermocouple wires.

The remaining parameters (thermal conductivities of cement mortar and thermal insulation, heat transfer coefficients on the face sides of the specimen) were set as free and served as instruments for the modification of the calculated temperature field. The highest correlation between the measured and calculated temperature fields can generally be achieved only when the values of free parameters are set as realistic as possible, including also the deviations caused by the experimental errors which can occur during the measurement. For example, the heat transfer coefficient between the insulation and laboratory air can be influenced by unexpected or random air flow in the laboratory. Moreover, the thermal conductivity of thermal insulation layer has to be identified in the form of an effective value, which includes both possible heat leakage through the gaps between the insulation and the opening frame and compression of the layer leading to an increase of body/air ratio. 
The optimal values of the four free parameters of the model were found using the genetic algorithm GRADE which was successfully applied in many engineering tasks before [18]-[19]. The scheme of the optimization process is given in Fig.6.

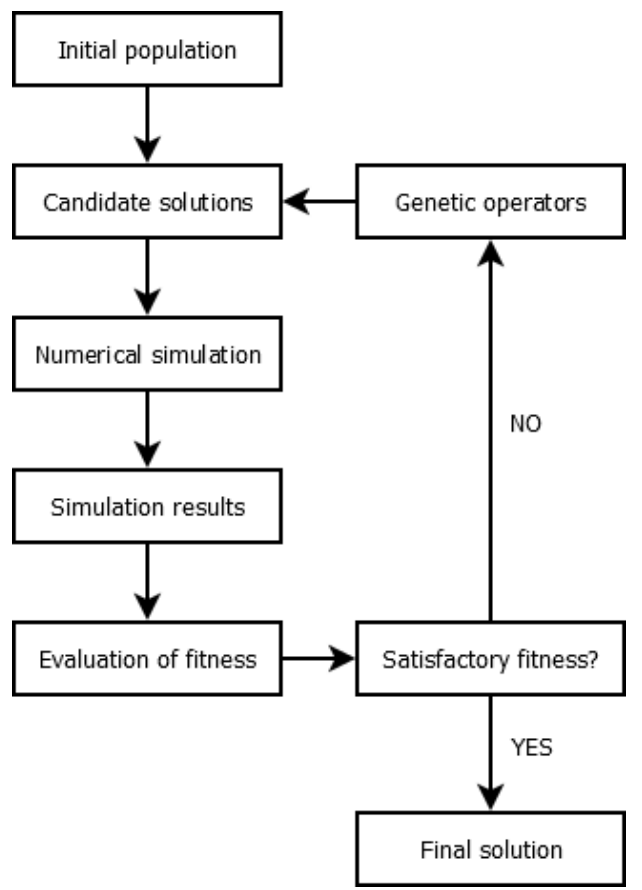

Fig.6. Scheme of the optimization process.

Each individual performed as a four-dimensional vector consisting of four free parameters that were to be optimized. The evolution started from randomly generated population and happened in generation. In each generation, the fitness function of every individual was evaluated. Multiple individuals were stochastically selected from the current population and modified using genetic operators such as mutation or cross-over to form new generation. The evaluation of the fitness function was based on the least square method between the measured and calculated temperatures. The objective of the optimization was to find such an individual that fulfilled the requirements for a satisfactory low fitness function value.

\section{RESULTS \& DISCUSSION}

The time record of measured temperatures between 17:00 and 8:00 of the following day in points A-F (see Fig.2.) is shown in Fig.7. Apparently, the temperature field inside the specimen reached the steady-state relatively fast, already after 20:00. The average values of steady-state temperatures including the standard deviation of the set of measurements are summarized in Table 3.

The accuracy of the temperature measurement by thermocouples can be influenced by several factors [20]. Therefore, IEC Standard 60584-2 [21] prescribes the maximal admissible error of K-type thermocouple, which can be expressed as $\pm 0.0075 \times|t|$. Using the standard deviation of the set of measurement and the maximal admissible error of data obtained by K-type thermocouple, the expanded uncertainty of temperature measurement at the confidence level of $99.7 \%$ can be calculated according to ISO/IEC 98-3, which is better known as GUM [22]. The results are presented in Table 4.

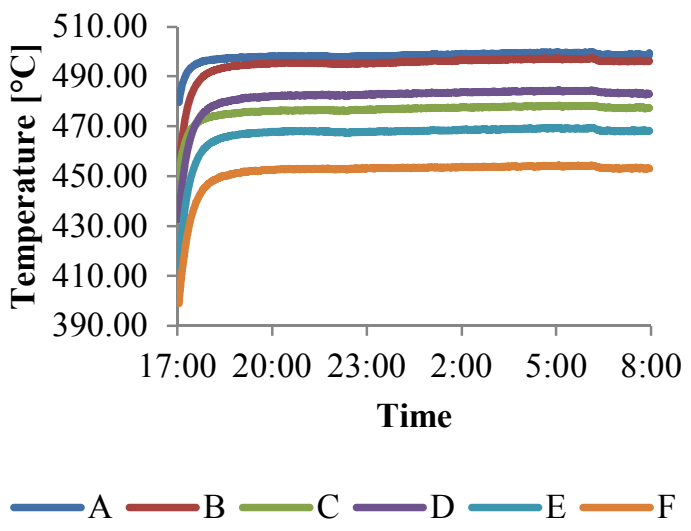

Fig.7. Results of the measurement of temperature field.

Table 3. Average values and standard deviations of steady-state temperatures.

\begin{tabular}{|c|c|c|}
\hline & Average temperature $\left[{ }^{\circ} \mathbf{C}\right]$ & Standard deviation $\left[{ }^{\circ} \mathbf{C}\right]$ \\
\hline A & 497.63 & 0.574 \\
\hline B & 495.07 & 0.701 \\
\hline C & 482.40 & 0.656 \\
\hline D & 476.28 & 0.699 \\
\hline E & 467.53 & 0.524 \\
\hline F & 452.88 & 0.477 \\
\hline
\end{tabular}

Table 4. Expanded uncertainty of temperature measurement.

\begin{tabular}{|l|c|c|}
\hline & Temperature $\left[{ }^{\circ} \mathbf{C}\right]$ & Expanded uncertainty $\left[{ }^{\circ} \mathbf{C}\right]$ \\
\hline A & 497.63 & \pm 6.47 \\
\hline B & 495.07 & \pm 6.44 \\
\hline C & 482.40 & \pm 6.27 \\
\hline D & 476.28 & \pm 6.18 \\
\hline E & 467.53 & \pm 6.08 \\
\hline F & 452.88 & \pm 5.88 \\
\hline
\end{tabular}

The measured positions of thermocouple points A-F were affected by uncertainties as well. Their calculation comes out from the standard deviation of the set of measurement (see Table 2.) and the maximal admissible error of digital caliper which is $0.03 \mathrm{~mm}$. The results of the uncertainty analysis are summarized in Table 5.

Table 5. Expanded uncertainty of length measurement.

\begin{tabular}{|c|c|c|}
\hline & Position [mm] & Expanded uncertainty [mm] \\
\hline a & 70.55 & \pm 0.20 \\
\hline b & 59.47 & \pm 0.16 \\
\hline c & 49.61 & \pm 0.23 \\
\hline d & 40.17 & \pm 0.18 \\
\hline e & 20.43 & \pm 0.20 \\
\hline f & 0.44 & \pm 0.15 \\
\hline
\end{tabular}


The summary of five sets of free parameters leading to the highest correlation between the measured and calculated temperature fields inside the specimen is given in Table 6 . The following symbols are used: $\lambda_{s}-$ thermal conductivity of the investigated specimen $[\mathrm{W} /(\mathrm{m} \cdot \mathrm{K})], \lambda_{i}-$ thermal conductivity of the thermal insulation $[\mathrm{W} /(\mathrm{m} \cdot \mathrm{K})], \alpha_{n}-$ the heat transfer coefficient at normal temperatures (outside the furnace) $\left[\mathrm{W} /\left(\mathrm{m}^{2} \mathrm{~K}\right)\right]$ and $\alpha_{h}-$ the heat transfer coefficient at high temperatures (inside the furnace) $\left[\mathrm{W} /\left(\mathrm{m}^{2} \mathrm{~K}\right)\right]$.

Table 6. Results of computational analysis - identification of free parameters.

\begin{tabular}{|l|c|c|c|c|c|}
\hline Step & $\mathbf{1}$ & $\mathbf{2}$ & $\mathbf{3}$ & $\mathbf{4}$ & $\mathbf{5}$ \\
\hline$\lambda_{s}$ & \multicolumn{5}{|c|}{$0.37-1.72$} \\
{$[\mathrm{~W} /(\mathrm{m} \cdot \mathrm{K})]$} & \multicolumn{5}{|c|}{} \\
\hline $\begin{array}{l}\lambda_{i} \\
{[\mathrm{~W} /(\mathrm{m} \cdot \mathrm{K})]}\end{array}$ & \multicolumn{5}{|c|}{} \\
\hline $\begin{array}{l}\alpha_{n} \\
{\left[\mathrm{~W} /\left(\mathrm{m}^{2} \mathrm{~K}\right)\right]}\end{array}$ & 6.4726 & 6.4760 & 6.4836 & 6.4634 & 6.4630 \\
\hline $\begin{array}{l}\boldsymbol{\alpha}_{\boldsymbol{h}} \\
{\left[\mathrm{W} /\left(\mathbf{m}^{2} \mathrm{~K}\right)\right]}\end{array}$ & $\mathbf{3 . 6 3 6 6}$ & $\mathbf{3 . 6 3 7 0}$ & $\mathbf{3 . 6 3 9 8}$ & $\mathbf{3 . 6 3 4 0}$ & $\mathbf{3 . 6 3 2 8}$ \\
\hline $\mathbf{R}^{2} \times \mathbf{1 0}^{2}$ & 92.37539 & 92.37536 & 92.37533 & 92.37531 & 92.37528 \\
\hline
\end{tabular}

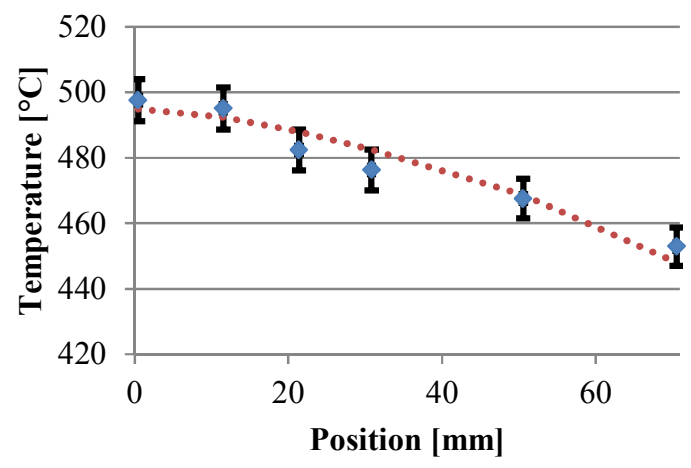

- Measurement $\ldots . .$. Calculation

Fig.8. Comparison of the measured and calculated temperatures for the best-found solution.

The comparison of the measured and calculated temperatures for the best-found solution is presented in Fig.8. It is obvious that all the calculated temperature values lie within the interval of confidence of the measured values.

The identified thermal conductivity of the investigated specimen corresponds to the temperature range achieved in the specimen during the experiment, which means approximately $440-500{ }^{\circ} \mathrm{C}$. Comparing this value with the results obtained by other researchers, a sufficient match was achieved, with respect to minor differences in specimens' composition, experimental setup or measurement method. For instance, Černý et al. [23] who measured thermal and hygric properties of cement mortar exposed to compressive stress and high temperatures between 175 and $800{ }^{\circ} \mathrm{C}$ found, that thermal conductivity of unloaded Portland cement mortar lies approximately between 1.4 and $1.5 \mathrm{~W} /(\mathrm{m} \cdot \mathrm{K})$ in the temperature range $430-500{ }^{\circ} \mathrm{C}$. This can be assumed as a very good agreement regarding the presence of plasticizer in the mortar mixture analyzed in this paper, which decreases the amount of water and thus the amount of pores in the hardened body. This is supposed to lead to a higher thermal conductivity of the mortar.

Thermal conductivity of the thermal insulation filling of the furnace door opening was found to be $0.30 \mathrm{~W} /(\mathrm{m} \cdot \mathrm{K})$. This value may seem to be too high at a glance, but it is important to note that it as an effective value which includes the effects of high temperature and heat leakage or deformations leading to a deterioration of thermal insulation properties. Possible heat leakage or material deformation can easily appear due to inaccurate shaping of the insulation which was done using a knife or scissors. The shape of the insulation is then not the same as the shape of the opening, thus it does not fit exactly and gaps or deformations may locally appear. If it is then exposed to high temperature, even small shape inaccuracy can lead to relatively high heat losses compared to the calculated results. According to the producer's statement, thermal conductivity of ceramic fibrous insulation may rise up to $0.2 \mathrm{~W} /(\mathrm{m} \cdot \mathrm{K})$ at $600{ }^{\circ} \mathrm{C}$ [24]. Generally, it lies between 0.09 and $0.35 \mathrm{~W} /(\mathrm{m} \cdot \mathrm{K})$ according to Spinnler et al. [25] and Huang and Yue [26], therefore the value $0.3 \mathrm{~W} /(\mathrm{m} \cdot \mathrm{K})$ found in this paper, which includes all the described phenomena and experimental errors, stands not significantly out of the usual range.

The best solution was found when the heat transfer coefficient at normal temperatures (between the thermal insulation layer and the laboratory environment) was between 6.4630 and $6.4836 \mathrm{~W} /\left(\mathrm{m}^{2} \mathrm{~K}\right)$. Koca et al. [6] reported that heat transfer coefficient was $8.16-$ $9.19 \mathrm{~W} /\left(\mathrm{m}^{2} \mathrm{~K}\right)$ in dependence on position of heated/unheated panels and windows. This value, measured at surface temperature less than $42{ }^{\circ} \mathrm{C}$, contains radiative as well as convective components, where radiative represents approximately $70 \%$. Because the convective component of the heat transfer coefficient may vary due to different experimental setup, different laboratory environment and other factors, the comparison cannot be performed precisely. The variability of the convective heat transfer coefficient was, among others, demonstrated by Kalema and Haapala [27], who compared their results with several independent measurements [28]-[29]. In the case of vertical walls, the results may vary up to $30 \%$. According to other investigators [30], the value of the heat transfer coefficient in the interior is usually about $8 \mathrm{~W} /\left(\mathrm{m}^{2} \mathrm{~K}\right)$, the same is prescribed in appropriate thermal standards [13], [31]. Therefore, one can conclude that the value of the heat transfer coefficient in normal temperature range obtained by our computational-experimental method was in a reasonable agreement with the data found in the relevant literature.

It is important to note that the heat transfer coefficient at high temperatures (inside the furnace), as it was determined in this paper $\left(\alpha_{h}=3.6366 \mathrm{~W} /\left(\mathrm{m}^{2} \mathrm{~K}\right)\right)$, contained virtually the radiative component only. The convective component could be neglected because the experimental setup did not allow any substantial air flow in the closed space of the furnace where, after the achievement of the steady state, the temperature field was almost homogeneous. Therefore, if the results should be applied, for instance in fire safety engineering, it would be essential to formulate an additional expression for the convective component because of the 
extensive air flow which occurs during a fire.

The convective heat transfer coefficient for natural convection can be expressed using the Nusselt number, which can be calculated using Rayleigh and Prandtl numbers (or Grashof number defined as the ratio of Rayleigh to Prandtl number) as it was demonstrated by Dascalaki et al. [32] who summarized several correlations between Nusselt and Grashof numbers at room temperatures depending on surface inclination, flow condition or fluid. In the high temperature range, a similar procedure can be applied, only the Prandtl and Rayleigh numbers have to be recalculated according to (2)-(3) for the known hightemperature properties of the air,

$$
\begin{array}{r}
\operatorname{Pr}=\frac{v}{\alpha}, \\
R a=\frac{g \beta}{v \alpha},
\end{array}
$$

where $v$ is the kinematic viscosity $\left[\mathrm{m}^{2} / \mathrm{s}\right], \alpha$ is the thermal diffusivity $\left[\mathrm{m}^{2} / \mathrm{s}\right], \mathrm{g}$ is the acceleration due to gravity $\left[\mathrm{m} / \mathrm{s}^{2}\right]$, and $\beta$ is the thermal expansion coefficient $[1 / \mathrm{K}]$.

In the case of forced convection, there are several ways how to express the convective heat transfer coefficient. The empirical expression based on wind tunnel measurements reported by Jürges [33] belongs to the easiest methods, requiring only the air flow velocity. The convective heat transfer coefficient is expressed as

$$
h_{c}=4.0 \mathrm{~V}+5.6 ; \mathrm{V} \leq 5 \mathrm{~m} / \mathrm{s}
$$

or

$$
h_{c}=7.1 V^{0.78} ; V \geq 5 \mathrm{~m} / \mathrm{s} \text {. }
$$

These formulas were originally designed for the calculation of the convective heat transfer coefficient on the exterior side of buildings, but their application on the interior side would be possible.

Another method, derived from the fluid flow in pipes, determines the Reynolds number which is then used for the calculation of the Nusselt number. In the case of forced convection and under presumption that the air temperature is higher than the temperature of the walls, the correlation between Nusselt, Reynolds and Prandtl numbers can be expressed according to Dittus and Boelter [34] as

where

$$
N u=0.02 \operatorname{Re}^{0.8} \operatorname{Pr}^{0.3},
$$

$$
R e=\frac{V D}{v}
$$

In (7), $V$ denotes the characteristic velocity of the air $[\mathrm{m} / \mathrm{s}]$ and $D$ is the characteristic length of the problem [m].

Knowing the Nusselt number for natural or forced convection, the convective heat transfer coefficient can be expressed as

$$
\alpha_{c}=\frac{N u \cdot D}{\lambda}
$$

where $\lambda[\mathrm{W} /(\mathrm{m} \cdot \mathrm{K})]$ denotes the thermal conductivity of the air.

\section{CONCLUSIONS}

A method for determining the radiative heat transfer coefficient at high temperatures was presented in the paper. It is based on a combination of experimental measurement of the temperature field inside the analyzed specimen and computational modeling of heat transfer including an optimization process performed using genetic algorithms. The results of the experimental measurement of temperature field inside the specimen supplemented by the uncertainty analysis serve as the input data for computational modeling involving four free parameters, namely the thermal conductivities of the specimen, the thermal insulation layer, and the heat transfer coefficients at normal and high temperatures. The heat transfer coefficient at high temperature is the demanded result of the presented approach, while the remaining free parameters are supposed to stay within an expected range.

The radiative heat transfer coefficient found in this paper for the air temperature of $600{ }^{\circ} \mathrm{C}$ was $3.64 \mathrm{~W} /\left(\mathrm{m}^{2} \mathrm{~K}\right)$. This number can be used, for instance, as an exact input parameter in sophisticated CFD fire safety modeling. It only has to be completed by the calculation of the convective heat transfer component which can be done using the wellknown methods.

The main advantage of the proposed method is a simple experimental setup and low demands on input parameters, such as the characteristics of involved materials.

\section{ACKNOWLEDGMENT}

This research has been supported by the Czech Science Foundation, under project No. 15-05791S.

\section{REFERENCES}

[1] Lu, H., Zhao, X.L., Han, L.H. (2011). FE modelling and fire resistance design of concrete filled double skin tubular columns. Journal of Constructional Steel Research, 67, 1733-1748.

[2] Nguyen, T.D., Meftah, F. (2014). Behavior of hollow clay brick masonry walls during fire. Part2: 3D finite element modeling and spalling assessment. Fire Safety Journal, 66, 35-45.

[3] Ariyanayagam, A.D., Mahendran, M. (2014). Numerical modelling of load bearing light gauge steel frame wall systems exposed to realistic design fires. Thin-Walled Structures, 78, 148-170.

[4] International Organization for Standardization. (2006). Fire safety engineering - Selection of design fire scenarios and design fires. ISO/TS 16733. Geneva.

[5] European Committee for Standardization. (2002). Eurocode 1: Actions on structures - Part 1-2: General actions - Actions on structures exposed to fire. EN 1991-1-2. Brussels. 
[6] Koca, A., Gemici, Z., Topacoglu, Y., Cetin, G., Acet, R.C., Kanbur, B.B. (2014). Experimental investigation of heat transfer coefficients between hydronic radiant heated wall and room. Energy and Buildings, 82, 211221.

[7] Cholewa, T., Rosiński, M., Spik, Z., Dudzińska, M.R., Siuta-Olcha, A. (2013). Energy and Buildings, 66, 599-606.

[8] Nsofor, E.C., Adebiyi, G.A. (2001). Measurements of the gas-particle convective heat transfer coefficient in a packed bed for high-temperature energy storage. Experimental Thermal and Fluid Science, 24, 1-9.

[9] Hong-Shun, L., Ren-Zhang, Q., Wen-Di, H., Kai-Jun, B. (1993). An investigation on instantaneous local heat transfer coefficients in high-temperature fluidized beds-II. Statistical analysis. International Journal of Heat and Mass Transfer, 36, 4397-4406.

[10] Bao, Z., Yang, F., Wu, Z., Cao, X., Zhang, Z. (2013). Simulation studies on heat and mass transfer in hightemperature magnesium hydride reactors. Applied Energy, 112, 1181-1189.

[11] Caron, E.J.F.R., Daun, K.J., Wells, M.A. (2014). Experimental heat transfer coefficient measurements during hot forming die quenching of boron steel at high temperatures. International Journal of Heat and Mass Transfer, 71, 396-404.

[12] Freund, S., Kabelac, S. (2010). Investigation of local heat transfer coefficients in plate heat exchangers with temperature oscillation IR thermography and CFD. International Journal of Heat and Mass Transfer, 53, 3764-3781.

[13] Czech Office for Standards, Metrology and Testing. (2011). Thermal protection of buildings - Part 2 . Requirements. CSN 73 0540-2. Prague.

[14] European Committee for Standardization. (1999). Methods of test for mortar for masonry - Part 10: Determination of dry bulk density of hardened mortar. EN 1015-10. Brussels.

[15] Kruis, J., Koudelka, T., Krejčí, T. (2010). Efficient computer implementation of coupled hydro-thermomechanical analysis. Mathematics and Computers in Simulation, 80 (8), 1578-1588.

[16] International Center for Numerical Methods in Engineering. (2014). GiD v12.0.1 Software. Barcelona, Spain.

[17] Sundqvist, B. (1992). Thermal diffusivity and thermal conductivity of Chromel, Alumel, and Constantan in the range 100-450 K. Journal of Applied Physics, 72 (2), 539-545.

[18] Hrstka, O., Kučerová, A., Lepš, M., Zeman, J. (2003). A competitive comparison of different types of evolutionary algorithms. Computers \& Structures, 81 (18-19), 1979-1990.

[19] Kočí, J., Žumár, J., Pavlík, Z., Černý, R. (2012). Application of genetic algorithm for determination of water vapor diffusion parameters of building materials. Journal of Building Physics, 35 (3), 238-250.

[20] Jun, S., Kochan, O. (2014). Investigation of thermocouple drift irregularity impact on error of their inhomogeneity correction. Measurement Science Review, 14 (1), 29-34.
[21] International Electrotechnical Commission. (1995). Thermocouples. Part 2: Tolerances. IEC Standard 60584-2. Geneva, Switzerland.

[22] Joint Committee for Guides in Metrology. (2008) Evaluation of measurement data - Guide to the expression of uncertainty in measurements. ISO/EIC Standard 98-3:2008.

[23] Černý, R., Totová, M., Poděbradská, J., Toman, J., Drchalová, J., Rovnaníková, P. (2003). Thermal and hygric properties of Portland cement mortar afetr hightemperature exposure combined with compressive stress. Cement and Concrete Research, 33, 1347-1355.

[24] Morgan Thermal Ceramics. (2009). Datasheet Code 5 5-01 E. http://www.morganthermalceramics.com/sites/ default/files/datasheets/cerablanketcerachemcerachrom eblanketenglish.pdf.

[25] Spinnler, M., Winter, E.R.F., Viskanta, R. (2004). Studies on high-temperature multilayer thermal insulations. International Journal of Heat and Mass Transfer, 47, 1305-1312.

[26] Huang, C., Yue, Z. (2014). Calculation of hightemperature insulation parameters and heat transfer behaviors of multilayer insulation by inverse problems method. Chinese Journal of Aeronautics, 27 (4), 791796.

[27] Kalema, T., Haapala, T. (1995). Effect of interior heat transfer coefficient on thermal dynamics and energy consumption. Energy and Buildings, 22, 101-113.

[28] American Society of Heating, Refrigerating and AirConditioning Engineers. (1981). ASHRAE Handbook: Fundamentals. Atlanta, GA.

[29] Khalifa, A.J.N., Marshall, R.H. (1990). Validation of heat transfer coefficients on interior building surfaces using real-sized indoor test cell. International Journal of Heat and Mass Transfer, 33, 2219-2236.

[30] Kočí, V., Maděra, J., Jerman, M., Trník, A., Černý, R. (2014). Determination of the equivalent thermal conductivity of complex material systems with largescale heterogeneities. International Journal of Thermal Sciences, 86, 365-373.

[31] European Committee for Standardization. (2008). Heating systems in buildings - Design of embedded water based surface heating and cooling systems Part 1: Determination of the design heating and cooling capacity. EN 15377-1. Brussels.

[32] Dascalaki, E., Santamouris, M., Balaras, C.A, Asimakopoulos, D.N. (1994). Natural convection heat transfer coefficients from vertical and horizontal surfaces for building applications. Energy and Buildings, 20, 243-249.

[33] Jürges, W. (1924). Der Wärmeübergang an einer ebenen Wand (heat transfer at a plane wall). Beihefte zum Gesundheits-Ingenieur, 1 (19).

[34] Dittus, F.W., Boelter, L.M.K. (1985). Heat transfer in automobile radiators of the tubular type. International Communications in Heat and Mass Transfer, 12 (1), 3-22.

Received December 08, 2014. Accepted April 30, 2015. 